Distribution Retrieval Engineering 73530

5. Proj./Prog./Dept./Div.:

6. Design Authority/ Design Agent/Cog. Engr.:

Waste Management

\section{EJ Berglin}

8. Originator Remarks:

This document is being processed for release.

11. Receiver Remarks:

11A. Design Baseline Document?

[] Yes

[X] No

\section{EDT 605669}

4. Related EDT No.:
N/A

9. Equĩp./Component Mo.: $N / A$

10. System/Bldg./Facility: $N / A$

12. Major Assm. Dwg. No.: $N / A$

13. Permit/Permit Application No.: $N / A$

14. Required Response Date: $N / A$

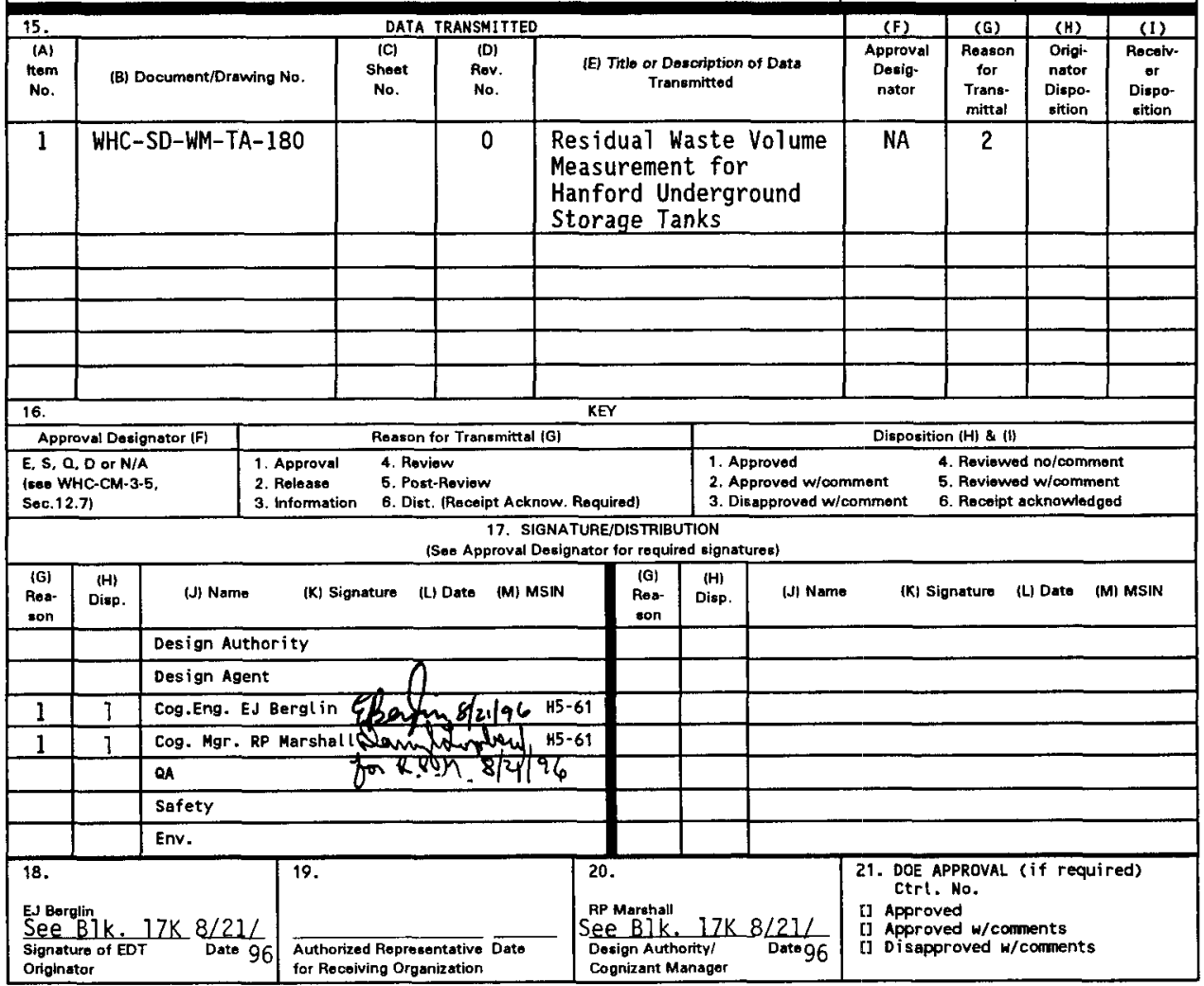




\title{
Residual Waste Volume Measurement for Hanford Underground Storage Tanks
}

\author{
Eric J. Bergl in
}

Westinghouse Hanford Company, Richland, WA 99352

U.S. Department of Energy Contract DE-AC06-87RL10930

$\begin{array}{llll}\text { EDT/ECN: } & 605669 & \text { UC: } & 2000 \\ \text { Org Code: } & 73530 & \text { Charge Code: } & \text { D2027 } \\ \text { B\&R Code: } & \text { EW3130010 } & \text { Total Pages: } & 17\end{array}$

Key Words: singte-Shell Jank, Waste Retrieval, SST, Residual Waste, Heel, Closure, Waste Thickness Measurement, Kinematic Based System, Global Positioning System, GPS, Waste surface Topology Mapping, Fringe Projection-based Structured Light System, Laser Range Finder, Stereo Vision, Ultrasonic, Water jet, Capacitance Sensor, Inductive Sensor, Ground Penetrating Radar, GPR, Magnetometer, Mechanical Probe, Acquire Commercial Technology for Retrieval, ACTR, Hanford Tank Initiative, HTI, Underground Radioactive Tank, Hanford

Abstract: The Acquire Commercial Technology for Retrieval program seeks commercial solutions to measure any waste residual (i.e., heel) left after waste retrieval operations of underground radioactive storage tanks. The technology identified should operate in a range of waste depth thickness of $0-6$ inches. This report provides a description of the need, requirements, and constraints for the residual waste volume measurement system; describes a logical approach to measuring waste volume; provides a brief review and assessment of available technologies; and outlines a set of integrated tests that will evaluate the performance of candidate technologies.

TRADEMARK DISCLAIMER. Reference herein to any specific commercial product, process, or service by trade name, trademark, manufacturer, or otherwise, does not necessarily constitute or imply its endorsement, recommendation, or favoring by the United States Goverrment or any agency thereof or its contractors or subcontractors.

Printed in the United States of America. To obtain copies of this document, contact: UHC/BCS Document Control Services, P.0. Box 1970, Mailstop H6-08, Richland WA 99352, Phone (509) 372-2420; Fax (509) 376-4989.
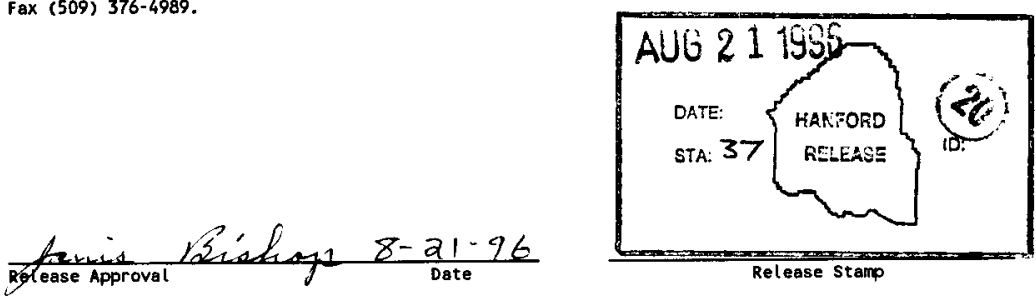

\section{Approved for Public Release}


UHC-SD-WM-TA-180, Rev. 0

\title{
Residual Waste Volume Measurement for Hanford Underground Storage Tanks
}

July 1996

Eric J. Berglin

prepared by

Dr. Mark Evans

Brigham Young University

Provo, Utah

\author{
for \\ Westinghouse Hanford Company \\ Richland, Washington
}


HHC-SD-WM-TA-180, Rev. 0

\section{CONTENTS}

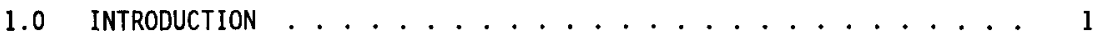

2.0 SYSTEM REQUIREMENTS AND ASSUMPTIONS . . . . . . . . . . . 1

2.1 MAXIMUM ALLOWABLE RESIDUAL WASTE VOLUME .......... 1

2.2 CLOSURE VS. RETRIEVAL OPERATION ............. 2

2.3 ACCURACY REQUIREMENTS ................. 2

2.4 STATISTICAL SAMPLING .............. 3

2.5 INITIAL CANDIDATE TANKS .............. 3

3.0 APPROACH TO WASTE VOLUME MAPPING ............. 3

4.0 TECHNOLOGY REVIEW ............................. 4

4.1 SENSOR POSITION DETECTION . . . . . ...... 4

4.2 WASTE SURFACE TOPOLOGY MAPPING SYSTEM $\ldots \ldots$

4.3 WASTE THICKNESS MEASUREMENT . ............ 8

5.0 CONCLUSIONS AND RECOMMENDATIONS ............. 11

6.0 REFERENCES ........................... 13 


\section{Abbreviations and Acronyms}

$\begin{array}{ll}\text { ACTR } & \text { Acquire Commercial Technology for Retrieval } \\ \text { AM } & \text { amplitude modulation } \\ \text { DOE } & \text { Department of Energy } \\ \text { FMCLR } & \text { frequency-modulated coherent laser radar } \\ \text { GPR } & \text { ground-penetrating radar } \\ \text { GPS } & \text { Global Positioning System } \\ \text { HTI } & \text { Hanford Tanks Initiative } \\ \text { LDUA } & \text { light-duty utility arm } \\ \text { NASA } & \text { National Aeronautics and Space Administration } \\ \text { ORNL } & \text { Oak Ridge National Laboratory } \\ \text { PNNL } & \text { Pacific Northwest National Laboratory } \\ \text { SNR } & \text { signal-to-noise ratio } \\ \text { TOF } & \text { time-of-flight } \\ \text { TMS } & \text { topology mapping system } \\ \text { SIR } & \text { subsurface interface radar } \\ \text { WHC } & \text { Westinghouse Hanford Company } \\ \text { WIPP } & \text { Waste Isolation Pilot Plant }\end{array}$

\section{Trademarks}

ARD Environmental, Inc. is not a trademark.

Coleman Research Corporation is not a trademark.

Lockheed Missiles and Space Company, Inc.is not a trademark.

Mechanical Technology, Inc. is not a trademark.

Odetics and Perceptron is not a trademark.

SPAR Aerospace Limited is not a trademark.

Waterjet Technologies, Inc. is not a trademark 


\section{WHC-SD-WM-TA-180, Rev. 0 \\ Residual Waste Volume Measurement for Hanford Underground Storage Tanks}

\subsection{INTRODUCTION}

Westinghouse Hanford Company (WHC) is exploring commercial methods for retrieving waste from the underground storage tanks at the Hanford site in south central Washington state. WHC needs data on commercial retrieval systems equipment in order to make programmatic decisions for waste retrieval. Full system testing (i.e., integrated components) of retrieval processes is to be demonstrated in phases through September 1997 in support of two related programs: 1) Acquire Commercial Technology for Retrieval (ACTR) and 2) the Hanford Tanks Initiative (HTI).

One of the important parts of the integrated testing will be residual waste volume mapping of the tank waste following the retrieval process as part of the closure operation. WHC requires an assessment of commercial and laboratory equipment that could be brought to an integrated cold test of waste volume mapping systems.

The objectives of this document are as follows: 1) to provide a description of the need, requirements, and constraints for a residual waste volume measurement system; 2) to describe a logical approach to measuring waste volume; 3) to provide a brief review and assessment of available technologies; and 4) to outline a set of integrated tests that will evaluate the performance of candidate technologies.

\subsection{SYSTEM REQUIREMENTS AND ASSUMPTIONS}

Some of the system requirements and the assumptions that have been used in the generation of this report are discussed below.

\subsection{MAXIMUM ALLOWABLE RESIDUAL WASTE VOLUME}

Remediation of the underground storage tanks at Hanford will require retrieval of nearly all of the waste. The Tri-party Agreement specifies that there shall be no more than $360 \mathrm{cu} f t$ of waste remaining in a tank for retrieval to be complete. As each tank is $75-\mathrm{ft}$ in diameter, the area of each tank floor is $4,418 \mathrm{sq} \mathrm{ft}$. If it is assumed that all of the residual waste is spread over the tank floor (i.e., the tank walls are completely clean) then this requirement translates to an average depth of residual waste over the entire tank floor of 0.98 in. It is probable that some waste will remain adhered to the tank walls, especially since the tanks have 3 in. $x 3$ in. angle hoop reinforcements welded to the tank wall every $3 \mathrm{ft}$ of vertical height. For the largest tanks, assuming a tank liner height of $40 \mathrm{ft}$, a reasonable estimate might be that only two-thirds of the residual waste is left on the 
floor of the tank. If this is the case then the thickness of waste on the tank floor will be 0.65 in.

For the purposes of this report, the average allowable residual waste thickness on the tank floor will be $0.65 \mathrm{in}$. It should also be noted that it is likely that the residual waste will not be distributed evenly over the entire surface of the tank floor. Some portions of the floor may have as much as ten times the average thickness of waste, while other portions may be bare. The systems used to measure waste thickness should therefore be capable of measuring waste thicknesses which vary from $0-6$ in.

\subsection{CLOSURE VS. RETRIEVAL OPERATION}

It is assumed for the purposes of this report that the measurement of residual waste volume will be done as part of the tank closure operation and not as part of the retrieval operation. This is an important distinction for several reasons. First, this allows the measurement of the waste volume to be performed independentiy from the retrieval of waste, and it therefore does not need to be performed in "real-time" (i.e., the rate of retrieval will not be affected by the rate of waste volume measurement). Secondly, the sensor systems will not be subject to harsh environmental conditions that may be temporarily generated by the retrieval process. For example, particles and mist will most likely be generated during the retrieval process if waterjet cutters or sluicing methods are used to dislodge waste. Using sensors for "real-time" control or monitoring operations would require adequate protection of the sensor from these particles or mists. Splatter is much less a problem if the sensor is used to determine the waste volume after or between actual retrieval operations. Thirdly, sensor systems that are not deployed during retrieval operations will not be subject to the vibrations and dynamic effects that may be caused by the reaction forces and torques generated by waste dislodging and conveying tools. Finally, the deployment requirements for systems used for determining waste volume can be considered separate from those required for retrieval systems.

\subsection{ACCURACY REQUIREMENTS}

Using the assumption that the average allowable residual waste thickness on the tank floor will be 0.65 in., the measurement system should be capable of one order of magnitude finer resolution, or 0.065 in. The most promising deployment system candidate for a residual waste thickness measurement system is the light-duty utility arm (LDUA) which is currently owned by WHC. The horizontal accuracy of the sensors in the measurement system should not detract from the accuracy of the overall measurement system by more than onetenth of the accuracy of the LDUA. The LDUA has a positioning accuracy of \pm 2 in. when deployed in a tank. 


\subsection{STATISTICAL SAMPLING}

While it is generally assumed that the floor of a tank liner may have warped over time, it is assumed for the purposes of this report that it will suffice to locate the floor of the steel liner at all areas reachable by the LDUA using existing tank riser entries. The location of the stee 7 liner in areas that are not reachable by the LDUA will be extrapolated using a smooth extension of the measured floor locations.

\subsection{INITIAL CANDIDATE TANKS}

The two initial candidate tanks for use of a residual waste volume measurement system are current $7 y$ tanks $C-106$ and AX-104. Tank $C-106$ current $1 y$ contains high-heat generating waste and any residual waste should be considered to have radiation levels in the range of $270-540 \mathrm{R} / \mathrm{hr}$. Tank construction drawings and photographs show that tank C-106 is mostly clear of fixed in-tank hardware (i.e., in-tank hardware that is attached to the tank such as instrument trees, pumps, pipes, air-lift circulators, etc.). On the other hand, tank $A X-104$ is known to have one of the highest densities of fixed in-tank hardware. Any residual waste volume measurement system must be capable of working in high radiation fields and be able to work around fixed in-tank hardware.

\subsection{APPROACH TO WASTE VOLUME MAPPING}

The measurement of residual waste volume is a two-step process. The first step is to measure the topology of the waste surface, and the second step is to determine the location of the steel liner beneath the waste surface. Several candidate sensor systems have been identified for each step. In order to register the two measured surfaces (the waste surface and the liner surface) either the position of the sensors with respect to each other must be determined, or the same sensor must be used to measure each surface from the same location. Regardless of the sensor systems used, the measurement of the residual waste volume will not be any more accurate than the ability to determine the location of the liner with respect to the waste surface.

The simplest and most effective method of registering the measurement of the liner location with the waste surface will be to have the sensor(s) that measure each be co-located or at a known fixed position relative to each other. In other words, the height of the waste surface and the location of the steel liner should be measured at the same time and from the same position above the waste surface.

Depending on the retrieval process used, the measurement of the waste surface topology may also have been done prior to closure. A topology map of the entire surface of the waste will be valuable for determining the areas of interest for waste thickness measurements. For example, if a topological map shows that a large mound (or a significant valley) exists in the residual waste, it may be desirable to take waste thickness measurements in those locations. If on the other hand, it shows that a significant portion of the 
WHC-SD-WM-TA-180, Rev. 0

surface is very nearly level, fewer thickness measurements may be needed in these areas. If mapping of the waste surface is not a part of the retrieval process, then for these reasons it will be helpful to perform this operation as part of the residual waste volume measurement.

It is assumed for the purposes of this report that the LDUA will be available as a deployment system for the sensors required to measure the waste volume. It is also assumed that there will be multiple access ports available for deployment of the system into any given tank.

\subsection{TECHNOLOGY REVIEW}

A survey of technologies that may be applicable to measuring the volume of residual waste in a tank following a retrieval operation is presented in the following sections. The sections are organized into three main groups: sensor position detection, waste surface topology mapping, and waste thickness measurement. In the area of sensor position detection, three types of sensors are reviewed: a kinematic-based system, and an in-tank global positioning system. In the area of waste surface topology mapping, four types of sensors are reviewed: line-based structured light, fringe projection-based structured 1 ight, laser range finders, and stereo vision systems. Finally, in the area of waste thickness measurement, which is really a detection of the steel liner through the waste, seven technologies are reviewed: ultrasonics, ultrasonics through a waterjet, capacitance type sensors, inductive sensors, ground penetrating radar, magnetometers, and mechanical probes.

Two earlier reports were used as significant references for the following technology reviews, particularly in the waste surface topology (Bernacki and Burks 1995) and waste thickness measurement areas (Thunborg 1994).

\subsection{SENSOR POSITION DETECTION}

Kinematic-based System: The simplest and most cost effective method of sensing the position of the sensor systems used will be the positioning system for the deployment system used. If it is assumed that the LDUA will be the deployment system, then the maximum accuracy that can be expected using this method will be the accuracy of the LDUA end-effector position feedback system. The LDUA uses a resolver-based position feedback system with an accuracy of \pm 2 in. and a repeatability of \pm 0.200 inches when fully deployed in a tank. Assuming that the same LDUA system is used to deploy the waste topology measurement system and the waste thickness measurement system, and if it is not sufficient to take measurements from the same locations for both systems, the accuracy of registration between the two systems will be one-half that of the LDUA positioning feedback system. If on the other hand, it is sufficient to take measurements from the same locations for both systems, the accuracy of registration between the two systems will be equal to the repeatability of the LDUA under this scenario. 
Advantages of a kinematic-based system include reduced cost and reduced complexity. Both cost and complexity would be reduced since the deployment system with its position feedback system will be a part of the measurement system regardless of whether an independent position detection system is employed or not. In addition, this method requires access to the tank through only one access port at a time. The main disadvantage of a kinematicbased system is the resolution.

In-tank Global Positioning System (GPS): An in-tank global positioning system would operate using the same principles as the world-wide giobal positioning system. In one scenario a sufficient number of "satellite" energy sources would be placed at various known and fixed locations in the dome of the tank, such that a direct line of sight to a minimum of three of these sources would be available at any location throughout the tank where waste volume measurements sensors would be positioned. A receiver would then be placed at the end-effector of the deployment system (the LDUA in this case), and the position of the end-effector would be determined from triangulation to at least three satellite sources. The other scenario that could be used would swap the roles of the sources and sensors (i.e., the "satellites" would be receivers and a source would be placed on the end-effector).

Several different energy sources have been used for local GPS systems including light, infrared, acoustic, and radio frequency sources. Some of the issues assocjated with local GPS systems include the effect of echoing in a closed space with steel walls, and the effect of shadowing due to in-tank hardware. While visual-based systems (light and infrared) should not have problems with echoing, they require a direct and unobstructed line of sight between sources and receivers. On the other hand, non-visual systems (acoustic and radio frequency) may not require the direct line of sight, but may be affected by echoing. It is not clear that local GPS is a technology that is currently available.

\subsection{WASTE SURFACE TOPOLOGY MAPPING SYSTEM (TMS)}

Line-based Structured Light System: In a line-based structured light system, a light source (typically a laser) is used to draw a stripe of light on the surface to be measured. A camera placed at a known distance and angle with respect to the light source is then used to view the stripe of light. Height variations in the surface being measured cause the image of the light stripe on the camera to deflect from a straight line. Knowing the separation and angle between the light source and the camera, the height associated with each illuminated camera pixel can be determined by triangulation. The light stripe is passed across the entire surface to be measured and the camera image is sampled at discrete intervals to build a map of the entire surface.

As part of the Department of Energy (DOE) Technology Development program, a TMS has been produced by Mechanical Technology, Inc. (MTI) which is a line-based structured light system. The TMS is self-contained, compact, reconfigurable, and capable of providing rapid variable-resolution mapping information of the waste surface in the Hanford underground storage tanks. This system is capable of mapping the surfaces on the floors, walls, and domes of each tank to a resolution of $1 \mathrm{in}$. with an accuracy of $\pm 0.25 \mathrm{in}$. at a range of $45 \mathrm{ft}$. The system is deployed independently of other equipment through an access port with a minimum diameter of 4 in. As indicated in the 
specifications for the system, the minimum data acquisition rate for mapping the floor of a 75- ft diameter tank is no more than 2 hours at a data density of one sample point per 6 in. by

6 in. area. This system is based on proven technology that has been used by the DOE at West Valley to measure the surface topology of waste in storage tanks.

As this system is now commercially available, and has been designed to be compatible with the environment within the Hanford tanks, it is recommended that this system be used to determine the waste surface topology.

Fringe Projection-based Structured Light System: Fringe projection is a variant of active triangulation that works by projecting an array of lines onto a scene and then viewing the image of the lines on the scene with a calibrated camera (Bernacki and Burks 1995).

In the study performed by Oak Ridge National Laboratory (ORNL) at the Pacific Northwest National Laboratory (PNNL), a fringe projection system developed by the Lockheed Missiles and Space Company showed impressive, dense, surface maps of objects within a limited range, and it was noted that the system can become confused by step discontinuities in the measurement surface, and cannot be reconfigured with respect to range and resolution in situ. It was also difficult to register the data collected by this system with a world coordinate frame. The system shows promise in applications needing high resolution within a narrow field of view - this is likely not the case when measuring the waste topology in a $75-\mathrm{ft}$ diameter underground tank. This technology may be useful however in measuring the 10cal topology where depth measurements are taken.

Laser Range Finders: Two general classes of laser range finders are discussed here, laser radar and active triangulation range finders, using synchronized scanners. The laser radars can be further classified into three types: time-of-flight (TOF), amplitude modulation (AM), or frequency-modulated coherent laser radar (FMCLR). A brief discussion of the advantages and disadvantages of both types is presented here.

The DOE Robotics Program has had extensive experience with TOF and AM range finders built by Odetics and Perceptron, and has evaluated an FMCLR from Coleman Research Corporation. The conclusion of the Robotics Program is that in general, the TOF and AM methods are not applicable to high-resolution surface mapping due to the low signal-to-noise ratio (SNR) inherent in these approaches, significant working distance requirements, and ambiguous range information, unless sophisticated encoding schemes are used. FMCLR has submillimeter resolution at working distances in excess of $15 \mathrm{~m}$, but at present, is a single-point measurement device requiring long mapping times. As a single-point measurement device with high accuracy, an FMCLR may be useful for measuring surface location at the point where depth measurements are taken.

For a detailed technical description of the active triangulation range finders using synchronized scanners (Bernacki and Burks 1995). SPAR Aerospace Limited has developed a laser range finder of this type based on technology licensed from the National Research Council of Canada. Based on the demonstration performed at PNNL, the SPAR laser range finder was found to be based on mature technology and to be more versatile than the fringe projection-based structured light system produced by Lockheed, or the stereo 
vision-based system produced by NASA. The following is quoted from the report of that demonstration:

- Based on a design first published in the literature in 1983, this technically mature approach is made more useful by the fullfeatured software that accompanied the laser range finder. One of the most impressive of these software functions is the ability to perform in-tank registration using known landmarks. This will clearly be the mode of operation during real remediation efforts. While there is always a tradeoff in data acquisition speed versus resolution, one can choose the resolution required for the task 'on the fly' without regard to recalibration. Also, since the method is a single point approach, discontinuities present no problem, and the signal to noise is inherently greater than methods that rely on projected stripes or grids."

Stereo Vision: A discussion of the stereo vision technology for 3-dimensional mapping is reproduced here (Bernacki and Burks 1995). A variant of active triangulation, this approach mimics the human vision system by using two cameras with known separation and relative angular offset to obtain range information from a scene. Also called stereo disparity, it gets its name from the following effect: If a three-dimensional object is viewed from two locations in a plane normal to the direction of vision, the image will shift its apparent position laterally when viewed from either position. Stereo vision devices exploiting stereopsis use two (or more) identical cameras to generate two disparity images. The placement of the cameras is crucial, since range measurement can only take $p l a c e$ in the region where the views of the two cameras overlap. A reference point that corresponds to the center of vision for each camera is determined from which the displacement of the point of interest is measured. The difference in the displacement of the two images, the focal length of the two cameras, and the distance between the two camera locations are then used to calculate the image. Range measurement is sensitive in the displacement or shear direction of the two images. If accurate range data is required in a direction perpendicular to camera planes, a third camera can be added.

Everett (1989) outlines four basic steps in the ranging process:

1. A point in the image of one camera must be identified and located.

2. The same point must be located in the image of the second camera.

3. The positions of the image points must be measured with respect to a common reference.

4. The distance to the point is calculated from the disparity measurement.

Although the above procedure appears straightforward, the very aspect that is being exploited, the disparity, makes it difficult to determine the location of the point of interest in the second image. The attempt to match the same point in the two images is called correspondence, which is currently an active area of research in stereo vision. To achieve correspondence, the same image point must be present in both views, which gives rise to the "missing parts" problem or shadowing common to all of the triangulation-type ranging methods. To reduce this effect, the baseline between the two cameras can be reduced, but this also reduces sensitivity. Also, matching is further complicated by variations in intensity of color between the two views, the 
presence of shadows in only one scene, changes in image characteristics caused by different viewing angles, or lighting effects. In the demonstration at PNNL, a stereo vision system primarily intended for collision avoidance was shown by representatives of NASA's Jet Propulsion Laboratory.

The conclusion of the ORNL study at PNNL (Bernacki and Burks 1995) was that a stereo vision system shows excellent aptitude for providing collision avoidance data, but that the data produced by such a system has insufficient resolution for world mapping tasks (i.e., topographical mapping of waste surfaces in large underground storage tanks).

\subsection{WASTE THICKNESS MEASUREMENT}

Ultrasonics through waste (Thunborg 1994): Ultrasonics is a viable solution for non-contact gage measurement to the first surface interface when the medium of transmission is known and characterized. To use ultrasonics as a means of sensing waste thickness through the waste would require impedance matching between the sensor and the waste material in order to transmit enough sonic energy into transmitted and reflected fields within the waste.

Impedance matching between air and solids or air and liquids is so poor that the transducer must be placed in contact with the solid or liquid. Often a transmission-enhancing medium such as an oil or grease is used to improve the coupling of the ultrasonic energy between the transducer and the solid under inspection. The inhomogeneity of the waste in terms of density, liquid and solid states, porosity, and other property variations increases the difficulty of using ultrasonics through the waste to determine thickness. This does not appear to be a viable solution for measuring waste thickness. The poor impedance matching between air and the waste does make this an excellent method for determining the surface of the waste at the discrete positions where depth measurements could be made with other types of thickness measurement sensors.

U1 trasonics through a waterjet (Telecon 6/17/98): Another approach for determining the location of the steel tank liner would be to use an ultrasonic sensor system coupled to a high pressure waterjet. This method would likely be ineffective in determining the location of the steel liner while the waterjet is in contact with the waste due to uncertainties in the physical properties of the waste, but as soon as contact is made with the steel liner the signature of the reflected signal would be very identifiable. The distance from the transducer to the liner could then be measured very accurately. A previously acquired topological map of the waste surface would provide the additional data necessary to determine the thickness of the waste. Previous studies have shown that non-abrasive high-pressure waterjets are very effective in cutting through the full spectrum of tank waste consistencies, but are non-damaging to the steel liner when in contact for only a short period of time (Telecon 6/20/96a).

The two main challenges to using ultrasonics through a waterjet are coupling the transducer to the jet, and noise in the reflected signal due to air bubbles in the stream. The challenge of coupling the transducer to the jet has been solved before by using a coupling rod to transmit signals between the transducer and the jet, thereby removing the transducer from the highpressure jet in order to reduce wear and noise. The number and size of air bubbles in the stream can be minimized by proper design of the nozzle. The 
effects of the air bubbles also decreases as the frequency of the acoustic signal is decreased. It is therefore likely that the signal to noise ratio can be maintained at a sufficiently high level by proper design of the nozzle and proper frequency selection.

Capacitance type sensors (Thunborg 1994): Capacitance sensors operate by generating a spatially-resolved electric field and measuring displacement current perturbations resulting from changes in the sensor/waste geometry and the waste composition. The sensitivity of the sensor is dependent on the interaction between the sensor electric field and the waste, and depends on the electrical properties of the waste. The application of capacitance-type sensors for thickness measurements is therefore dependent on the conductivity of the waste - a property that has not been quantified, and which is likely to vary throughout the non-homogeneous waste. Also the conductivity is likely to increase as the water content of the waste goes up. Significant experimentation would be required to determine the effect of different waste types and to calibrate such a sensor system.

Inductive sensors (Thunborg 1994): Inductive coupling devices are commonly employed in metal detectors used by beachcombers and treasure hunters. The device consists of two coils, usually concentric, and electronics to provide an alternating current signal to one coil and measure the resulting voltage on the other coil. The output voltage of the secondary coil is a measure of the inductive coupling between the coils. When no metal is present, the two coils are an air core transformer with relatively poor coupling between the coils. When a piece of metal is placed in the proximity of the coils the metal acts as a core for the transformer and the coupling between the coils increases dramatically, providing a change in the output of the second coil. Since the coupling between the two coils is through the magnetic fields, ferromagnetic materials produce much larger signals than other metals. The output voltage is a single value, and therefore, the size, shape, and distance to a buried piece of metal cannot be uniquely determined.

The inability to determine range for an inductive sensor when applied in conventional applications would appear to preclude their use in locating the steel liner of an underground storage tank through a layer of waste. However, underground storage tanks have a unique feature in that they have an essentially infinite flat plate of ferrous metal. It is possible that a closed form solution exists for the amount of coupling between two coils of known geometry and an infinite flat plate. Some research and development would be required to develop an inductive sensor that could determine the range to a flat steel plate through the waste.

Another difficulty associated with using an inductive sensor device in this application is that such a device would respond to all nearby metal objects. The presence of metal in the sensor deployment system (in this case the LDUA to start with) could cause significant errors in the measurements. This problem is compounded by the fact that the configuration of a manipulator (or other deployment device) changes with time, therefore it would not create a constant offset voltage that could be subtracted from the signal. Another possible variable would be the presence of rebar in the concrete structure beneath the steel liner - this could also have an effect on the sensor output. 
Ground-penetrating Radar (Thunborg 1994): Ground-penetrating radar (GPR) is currently being used in several applications where measuring layer thickness is required. One application is the measurement of asphait thickness on highways. Another is measuring salt layer thickness at the Waste Isolation Pilot Plant (WIPP). GPR systems, specifically called subsurface interface radar (SIR), for applications such as these are available commercially. In the underground storage tank application the interface between the waste and tank bottom is very distinctive; much more distinctive than the interface sought in the above applications.

The problem with GPR is that it does not work when used on conductive mediums. Normally a conductivity of less than 10 millisieman per meter is desirable. Conductivities higher than $10 \mathrm{~ms} / \mathrm{m}$ result in decreasing performance of the GPR. Waste in the tanks is expected to contain salts, which have a low conductivity when dry, but entrained water or water added during retrieval operations would likely result in a waste with a high conductivity.

To determine the thickness of the waste, the dielectric constant for the waste would need to be known. Measurement of the dielectric constant would likely be a problem, especially since the waste is not homogeneous.

Magnetometers (Thunborg 1994): A magnetometer measures the local magnetic field strength and gradient (or change in magnetic field). It is able to detect buried ferrous objects by measuring the magnetic field of the objects. Multiple measurements of gradient in different directions can give a complete measurement of the magnetic field at the point of measurement. Magnetometers are extremely sensitive to small changes in magnetic fields. They are frequently used to detect buried objects and, in general, are much more sensitive than inductively coupled metal detectors.

Because magnetometers are extremely sensitive, they require precise knowledge of the residual magnetic field around an object in order to determine range. The residual magnetism is a function of the level at the time the steel was manufactured and of the induced effect of the environment and the field around the tank. Residual magnetism may vary from tank to tank and within a single tank. Determination of the magnetic field for each tank to the accuracy required is likely to be such a major problem that it is not practical. Consequently, magnetometers appear to be poorly suited to the measurement of residual waste thickness.

Another problem with magnetometers for this application is that their ability to penetrate through the waste will be dependent on the waste permeability. If the waste were to have a somewhat consistent permeability it could be easily accounted for through calibration (Telecon 6/20/96b). Due to the unknown nature of much of the waste, along with its non-homogeneous nature, this may pose a significant problem.

Mechanical Probes: A mechanical probe would be pushed through the waste (perhaps assisted by a drilling motion for hard waste forms) until it comes in contact with the steel liner. The location of the steel liner would be determined by knowing the distance to the end of the probe. The major technical concerns for a mechanical probe would be the ability to push (or dri11) through the waste without significant potential for damaging the steel 
liner when contact is made, the ability to sense contact with the liner, and the time required for each measurement.

Two possible methods exist for providing a means of penetrating the waste with a mechanical probe without damaging the liner. In the first method, proposed by ARD Environmental (Telecon 6/21/96 and Telecon 7/11/96), the mechanical probe would consist of a drill with a tip made of a material that would be cut through the waste (even hard saltcake) and at the same time be soft enough that it would not be capable of damaging the 1 iner. ARD Environmental has developed such probes in the past for sludge in the bottom of petroleum tanks, and therefore this would involve a custom design effort rather than a technology development effort on their part. In the second method, the mechanical probe would use high-pressure waterjets to cut the waste as it is fed through to the steel liner. As mentioned earlier, it has been demonstrated that non-abrasive waterjets are very effective at cutting the waste while posing no threat to the integrity of the liner (Telecon $6 / 20 / 96 a)$.

Simple methods exist for sensing contact with the steel liner. Possibly the most effective method, would be to use a conductivity probe. This would involve making contact with a known portion of the liner and then completing a circuit by contacting the liner with the probe. Although the waste may be conductive due to the dissolved salts, the conductivity would increase dramatically the instant that contact is made with the liner. This has been verified on a small scale by measuring the conductivity through salt water in a metal container. In saturated salt water, it was determined that the electrical resistance dropped dramatically when a conductivity probe came in contact with steel after passing through the salt water; an approximate six orders of magnitude decrease was noted (Notebook 1996). An extra benefit of using a conductivity probe would be the ability to sense the surface of the waste with the same device that is measuring the position of the liner. While the conductivity of the waste will be much lower than that of the steel liner, it will also be much greater than that of air. One conductivity probe should be capable of sensing both the surface of the waste and the steel liner.

The amount of time required for each measurement will be dependent on several factors including the thickness and the hardness of the waste. Considering that the maximum thickness of waste being considered for this application is 6 in., the time required for each measurement should not be significant. Actual testing is required to determine the actual time requirements.

\subsection{CONCLUSIONS AND RECOMMENDATIONS}

Based on the above discussions, the following conclusions and recommendations are made:

Conclusion la: An overall topological map of the waste surface will be necessary to plan the measurement of residual waste thickness in such a manner as to satisfy all concerned parties that the waste thickness measurements taken are sufficient to provide a basis for calculating the residual waste volume. If such a map is not generated as part of the waste retrieval 
process, then it should be generated as part of the closure process prior to residual waste volume measurement.

Conclusion 1b: Several methods for building a topological map of the waste surface have been reviewed in this report including a line-based structured light system, a fringe projection-based structured light system, various kinds of laser range finders, and stereo machine vision systems. Of these methods the line-based structured light system appears to be the most mature and technically feasible method at this time.

Recommendation 1: Mapping of the residual waste surface; whether performed as part of retrieval or closure, should be done using the TMS line-based structured light system that has been developed by MTI under the Technology Development Program. This system uses a method that has been shown to be effective in tanks at West Valley, the development of which the DOE has already paid for, and which will be available for at least cold testing at Hanford by the end of FY 1996.

Conclusion 2: The simplest and most cost effective method of sensing the position of the sensor systems used for waste volume measurement will be the position sensing system for the deployment system used. Technical questions remain for the other type of system reviewed (an in-tank global positioning system), and the accuracy of the deployment system should be sufficient for this application.

Recommendation 2: The position and orientation of the waste thickness measurement sensors should be determined using the position sensing system of the deployment system. Use of such a system will not require any further development and will provide sufficient accuracy.

Conclusion 3: of the technologies reviewed in this report for measurement of the waste thickness (ultrasonics through the waste, ultrasonics through a waterjet, capacitive-type sensors, inductive sensors, ground-penetrating radar, magnetometers, and mechanical probes), the two with the highest probability of success are the mechanical probe and the use of ultrasonics through a waterjet. Each of the other technologies require a greater knowledge of the physical and/or chemical properties of the waste than is currently available. Of the two, the mechanical probe using a conductivity sensor to sense the surface of the waste and the steel liner is the simplest method requiring the minimum of custom design and testing. Both methods would require very little if any technology development.

Recommendation 3: A testing and demonstration phase should be entered into where the mechanical probe and the ultrasonics through a waterjet can each be evaluated. Although other vendors may also be capable of providing such systems, ARD Environmental is recommended as a possible provider for a mechanical probe, and Waterjet Technologies, Inc., formerly Quest, is recommended as a provider of the ultrasonic waterjet probe (possibly teamed with ultrasonic measurement consultants at the PNNL). 


\subsection{REFERENCES}

Bernacki, B. E., and B. L. Burks, 1995, DRAFT, A Comparison of Three Optical Ranging and Mapping Approaches Having Applications in Robotic Waste Remediation, Appendix 1, Oak Ridge National Laboratory, Oak Ridge, Tennessee.

Everett, CDR H.R., 1989, Survey of Collision Avoidance and Ranging Sensors for Mobile Robots, Robotics Autonomous Systems, Vol. 5, pp. 5-67.

Notebook, 7/12/96, Dr. Mark Evans, Laboratory Notebook, p 26, Brigham Young University, Provo, Utah.

Telecon, 6/17/96, Dr. Steve Doctor, Pacific Northwest National Laboratory, Richland, Washington, Dr. Mark Evans, Brigham Young University, Provo, Utah.

Telecon, 6/20/96a, Mike Rinker, Pacific Northwest National Laboratory, Richland, Washington, Dr. Mark Evans, Brigham Young University, Provo, Utah.

Telecon, 6/20/96b, Jerry Sandness, Pacific Northwest National Laboratory, Dr. Mark Evans, Brigham Young University, Provo, Utah.

Telecon, 6/21/96, Seymore (Sy) Kotler, ARD Environmenta1, Laure1, Maryland, Dr. Mark Evans, Brigham Young University, Provo, Utah.

Telecon, 7/11/96, Jim Ridgely, ARD Environmental, Dr. Mark Evans, Brigham Young University, Provo, Utah.

Thunborg, Siegfreid, 1994, A Review of Technology for Verification of Waste Removal from Hanford Underground Storage Tanks (WHC Issue 30), Appendix 2,

SAND94-1235, Sandia National Laboratory, Livermore, Cal ifornia.

\section{CONTACTS}

Coleman Research Corporation, 6551 Loisdale Court, Suite 800, Springfield, VA 22150 .

Lockheed Missiles and Space Company, Inc., Research and Development, Attn:

Rebecca L. Welling, 3251 Hanover Street, Palo Alto, CA 94304-1191.

NASA, Jet Propulsion Laboratory, Attn: Dr. Larry Matthies, MS107-102, 4800 Oak Grove Dr., Pasadena, CA 91109

SPAR Aerospace Limited, Attn: Julian Millard, 9445 Airport Road, Brampton, Ontario, Canada L6S 4J3. 


\section{DISTRIBUTION SHEET}

\begin{tabular}{|c|c|c|c|c|c|}
\hline \multirow{2}{*}{$\begin{array}{l}\text { To } \\
\text { Distribution }\end{array}$} & \multirow{2}{*}{\multicolumn{3}{|c|}{$\begin{array}{l}\text { From } \\
\text { Retrieval Engineering } 73530\end{array}$}} & \multicolumn{2}{|l|}{ Page 1 of 1} \\
\hline & & & & \multicolumn{2}{|c|}{ Date $8 / 20 / 96$} \\
\hline \multicolumn{4}{|l|}{ Project Title/Work Order } & \multicolumn{2}{|c|}{ EDT No. 605669} \\
\hline \multicolumn{4}{|c|}{$\begin{array}{l}\text { Residual Waste Volume Measurement for Hanford Underground } \\
\text { Storage Tanks/D2027 WHC-SD-WM-TA-180, Rev. } 0\end{array}$} & \multicolumn{2}{|l|}{ ECN No. } \\
\hline Name & MSIN & $\begin{array}{c}\text { Text } \\
\text { With All } \\
\text { Attach. }\end{array}$ & Text Only & $\begin{array}{c}\text { Attach./ } \\
\text { Appendix } \\
\text { Only }\end{array}$ & $\begin{array}{l}\text { EDT/ECN } \\
\text { Only }\end{array}$ \\
\hline $\begin{array}{l}\text { J. W. Bailey } \\
\text { E. J. Berglin } \\
\text { P. W. Gibbons } \\
\text { D. B. Hagmann } \\
\text { B. K. Hatchel } \\
\text { J. S. Hertzel } \\
\text { E. J. Kosiancic } \\
\text { R. P. Marshall } \\
\text { L. B. McDaniel } \\
\text { G. A. Meyer } \\
\text { D. L. Morgan } \\
\text { D. C. Ramsower } \\
\text { M. W. Rinker } \\
\text { W. R. Wrzesinski } \\
\text { J. A. Yount } \\
\text { Central Files }\end{array}$ & $\begin{array}{l}\text { S2-48 } \\
H 5-61 \\
H 5-61 \\
H 5-61 \\
K 5-26 \\
H 5-61 \\
H 5-61 \\
H 5-61 \\
H 5-61 \\
S 2-48 \\
G 6-55 \\
H 5-61 \\
K 5-22 \\
S 7-53 \\
H 5-61 \\
A 3-88\end{array}$ & $\begin{array}{l}x \\
x \\
x \\
x \\
x \\
x \\
x \\
x \\
x \\
x \\
x \\
x \\
x \\
x \\
x \\
x \\
x\end{array}$ & & & \\
\hline
\end{tabular}

